\title{
Chikungunya Disease Awareness Among U.S. Travelers to Caribbean Destinations
}

\author{
Oghenekaro Omodior ${ }^{*}$, Lori Pennington-Gray ${ }^{2}$, Stephen Holland², Brijesh Thapa ${ }^{2}$, Spiro Kiousis ${ }^{3}$ \\ ${ }^{1}$ Department of Recreation, Park and Tourism Studies, School of Public Health, Indiana University Bloomington, Bloomington, USA \\ ${ }^{2}$ Department of Tourism, Recreation \& Sport Management, University of Florida, Gainesville, USA \\ ${ }^{3}$ College of Journalism and Communications, University of Florida, Gainesville, USA
}

Corresponding Author: Oghenekaro Omodior, Assistant Professor; Department of Recreation, Park and Tourism Studies, School of Public Health, Indiana University Bloomington, Bloomington, USA. Tel: +1-812-856-7031, Email: oomodior@indiana.edu

Received December 17, 2016; Accepted December 31, 2016; Online Published February 19, 2017

\begin{abstract}
Introduction: This study investigated chikungunya disease awareness and its predictors, the level of adoption of recommended personal protective behaviors against chikungunya, and the health information-seeking behavior of U.S. travelers to Caribbean destinations.

Methods: A cross-sectional retrospective online survey of 653 adult U.S. international travelers who visited any one of 34 Caribbean destinations was conducted in October 2015. Study participants were recruited through Amazon ${ }^{\circledR}$ Mechanical Turk. Travelers who met the inclusion criteria and gave informed consent were subsequently redirected to complete the survey which was domiciled in Qualtrics ${ }^{\circledR}$.

Results: Results regarding health information-seeking behavior indicated that $51 \%$ of study participants had never sought information about chikungunya or any vector-borne illnesses. Only thirty percent of study participants reported having heard of chikungunya disease before participating in this study. After adjusting for the presence of other variables in a logistic regression model, gender of female, higher levels of education, more time spent at the destination, and a higher number of hours spent engaging in outdoor activities were factors significantly associated with chikungunya disease awareness. Study results also showed that twenty-two percent of study participants did not engage in any of the three recommended personal protective behaviors under investigation.

Conclusion: Study findings highlighted a gap in existing approaches to health information dissemination vis-à-vis adoption of recommended personal protective behaviors, especially for U.S. travelers at risk for chikungunya and other emerging mosquitoborne infectious diseases in Caribbean destinations.

Keywords: Chikungunya awareness, U.S. travelers, Caribbean destination, Personal-protective behavior
\end{abstract}

Citation: Omodior O, Pennington-Gray L, Holland S, Thapa B, Kiousis S. Chikungunya disease awareness among U.S. travelers to caribbean destinations. Int J Travel Med Glob Health. 2017;5(1):20-27. doi:10.15171/ijtmgh.2017.04.

\section{Introduction}

Chikungunya virus (CHIKV) is an alphavirus transmitted to humans through a bite from an infected Aedes aegypti or Aedes albopictus mosquito. ${ }^{1-4}$ With an estimated 3.6 billion people living in 124 countries considered at risk for the disease, outbreaks are characterized by rapid spread and infection rates reported to be as high as $75 \%{ }^{3,5}$ Although infection with the disease has been reported among travelers from different parts of the globe for decades, ${ }^{6}$ the first known cases of local transmission of chikungunya in the Western hemisphere were reported in December 2013 on the Caribbean island of St. Martin. Within a period of four months, there were over 31000 confirmed and probable cases reported from several other Caribbean islands. ${ }^{3,7}$

Beginning in 2014, soon after the disease appeared at Caribbean destinations, cases were identified among U.S. travelers returning from that region, and nearly 8000 travelrelated cases were reported across several U.S. states and territories. ${ }^{6}$ It is expected that the number of U.S. travelers to and from Caribbean destinations will continue to increase, due in part to the close proximity of the region to the U.S., the short flight distance from the continental U.S., and the fact that several islands rank among the most tourism-developed islands in the world. ${ }^{8}$

Statistics from the Caribbean Tourism Organization indicate that approximately 10 million visitors from the U.S. arrived 
in the Caribbean islands in 2014. ${ }^{9}$ The evidence suggests that for U.S. travelers and tourists to Caribbean destinations, participation in outdoor activities - a major lifestyle activity in the region - is the foremost attraction, and these activities put them at risk of exposure to mosquitoes responsible for the transmission of chikungunya disease. ${ }^{10,11}$

Given the absence of licensed vaccines or specific drug treatments for chikungunya infection, the Centers for Disease Control and Prevention (CDC) has focused on, among other things, raising awareness among both healthcare providers and the traveling public. ${ }^{12}$ Specifically, residents and travelers to areas in the tropics where chikungunya disease is prevalent were encouraged to adopt personal protective behaviors and mosquito avoidance strategies to prevent infection. Such strategies include using appropriate mosquito repellent on skin or clothing, wearing loosely-fitting long-sleeved shirts, pants, hats, and boots as weather permits when outdoors, sleeping under mosquito-repellent bed nets, using spatial repellents when indoors, staying in residences with air conditioning and screens on doors and windows, ${ }^{6,13}$ and using other control efforts aimed at reducing mosquito abundance. ${ }^{12}$

In the absence of an existing vaccine or treatment for chikungunya, the goal is to increase adoption of the recommended personal protective behavior ${ }^{13,14}$ among U.S. travelers to Caribbean destinations who constitute a population especially at risk. Although the U.S. CDC ${ }^{15,16}$ has embarked on a chikungunya awareness campaign for U.S. travelers to and from Caribbean destinations, the level of chikungunya awareness and the extent to which travelers to Caribbean destinations adopt the recommended personal protective behaviors remain unknown. Equally unknown are the level of participation in outdoor activities and the health information-seeking behavior of U.S. travelers to Caribbean destinations. This knowledge should provide a snapshot of risk/protective factors for chikungunya infection among such travelers. Additionally, such information can serve as a basis for the evaluation of existing health promotion programs aimed at preventing chikungunya infection among vulnerable populations while providing baseline data that can be used to inform future interventions.

This study purposed to describe U.S. travelers to Caribbean destinations - a known endemic region for chikungunya in relation to (1) chikungunya disease awareness and its predictors, (2) level of adoption of recommended personal protective behaviors, (3) participation in outdoor activities, and (4) health information-seeking behavior for chikungunya. The 3 recommended personal protective behaviors of interest are (a) use of insecticides or repellents on skin or clothing, (b) wearing loosely-fitting long-sleeved shirts, long pants, hats, and boots as weather permits, and (c) sleeping under mosquito-repellent bed nets or using spatial repellents when indoors. ${ }^{13}$

\section{Methods}

This cross-sectional retrospective survey was conducted on U.S. travelers/tourists to any one of 34 Caribbean destinations for leisure/business. "Caribbean destinations" as used in this discussion refers to the countries that are members of the CTO (see Supplementary file 1 for a list of the countries). ${ }^{9}$ Study participant inclusion criteria were an age greater than 18 years, currently living in the United States, and having traveled to one of the aforementioned Caribbean destinations in the last year for leisure/vacation. Exclusion criteria were reported travel in the past year, but not to one of the listed destinations; travel, but not currently living in the United States; and travel to the destination, but no reported participation in activities which might have led to exposure to mosquitoes. For this study, a "traveler/tourist" is defined as an individual who has traveled from the United States to one or more Caribbean island destinations and participated in recreation activities or rented or leased transient accommodations for a term of 6 months or less ${ }^{17}$ within the previous year.

The survey instrument contained 2 screening questions, 5 general descriptive questions, and 2 attention-trap questions. The attention-trap questions were included for the purpose of identifying and screening out unengaged responses. An example of an attention-trap question is "Answer North America for this question, if you're paying attention." Respondents who did not select North America from the list of 5 options were dropped from further participation in the study. Thirty-two response options were used to measure respondents' participation in outdoor activities (see Supplementary file 1). The list of outdoor activities was compiled based on the classifications of Hendee, Gale, ${ }^{18}$ and Kil, Holland. ${ }^{19}$ The awareness of study participants about chikungunya disease was measured as a dichotomous (Yes, No) variable using the question, "Have you heard about chikungunya disease before today?" Chikungunya awareness was dummy coded ( $1=$ "Yes", $0=$ "No") with the "No" responses used as the reference group in a multivariate logistic regression model. The 3 recommended personal protective behaviors (PPBs) were measured as dichotomous (Yes, No) variables using the following questions: "Which of the following behaviors did you practice on your last trip to the Caribbean destination(s) mentioned previously: (1) using insecticides and repellents on skin or clothing when outdoors at my primary Caribbean destination, (2) using bed nets, mosquito nets, insecticides or spatial repellents when indoors at my primary Caribbean destination(s), (3) Always wearing long pants, long-sleeved shirts, boots, or a hat when I was outdoors at my primary Caribbean destination(s)." All other survey items were pulled from existing instruments and research with known validity and reliability. ${ }^{19,20}$

The survey instrument was domiciled in Qualtrics (http:// www.Qualtrics.com) and study participants were recruited through Amazon ${ }^{\circledR}$ Mechanical Turk ([MTurk], www.mturk. amazon.com), an online research participant recruitment platform. Participation in this study was completely voluntary. Those who elected to participate and provide signed informed consent were enrolled in the study. Data was subsequently collected after checking that participants had met the inclusion criteria. All data cleaning, processing, and statistical analyses were performed using Microsoft Excel ${ }^{\circledR}$ 2013 and $\operatorname{SPSS}^{\circledR}$ Statistics version 22.

\section{Results}

A total of 734 qualified respondents participated in the online survey over a period of 5 days. Using multiple screening criteria such as deleting missing variables and unengaged responses, the final sample size decreased to 653 (89\%). 
The mean age of study participants was 32 years $(\mathrm{SD}=8.6)$. The mean duration of stay (in days) at the Caribbean destination was $9(\mathrm{SD}=8.8)$. The median number of hours spent engaging in outdoor activities was 25 (mean $=37$, $\mathrm{SD}=52.3$, range $=1-600$ hours). Fifty-five percent (361) of study participants reported their gender as male, 38\% (248) reported as females, and 7\% (44) did not indicate their gender (Table 1). In all, 93\% (606) of study participants said their purpose for travel to the Caribbean destination was for leisure, 4\% (26) traveled for business, and 3\% (19) traveled for both business and leisure, while only less than $1 \%$ (2) traveled for other reasons.

Table 1. Demographic Characteristics of Study Participants

\begin{tabular}{|c|c|}
\hline Variable & No. $(\%)$ \\
\hline \multicolumn{2}{|l|}{ Gender } \\
\hline Male & $361(55)$ \\
\hline Female & $248(38)$ \\
\hline Unknown & $44(7)$ \\
\hline \multicolumn{2}{|l|}{ Race } \\
\hline White/European American & $461(71)$ \\
\hline African American & $957(9)$ \\
\hline Asian & $55(8)$ \\
\hline Latino/Latina & $37(6)$ \\
\hline Others & $3(<1)$ \\
\hline Missing & $37(6)$ \\
\hline \multicolumn{2}{|l|}{ Education } \\
\hline High School diploma & $94(14)$ \\
\hline 2-year college degree & $114(18)$ \\
\hline 4-year college degree & $332(51)$ \\
\hline Graduate degree & $76(12)$ \\
\hline Missing & $37(6)$ \\
\hline \multicolumn{2}{|l|}{ Annual Household Income } \\
\hline Less than $\$ 25000$ & $69(11)$ \\
\hline$\$ 25001-\$ 50000$ & $197(30)$ \\
\hline$\$ 50001-\$ 75000$ & $184(28)$ \\
\hline$\$ 75001-\$ 100000$ & $90(14)$ \\
\hline$\$ 100001+$ & $71(11)$ \\
\hline Missing & $642(6)$ \\
\hline \multicolumn{2}{|l|}{ Purpose of trip } \\
\hline Leisure & $606(93)$ \\
\hline Business & $26(4)$ \\
\hline Business and leisure & $19(3)$ \\
\hline Others & $2(<1)$ \\
\hline \multicolumn{2}{|l|}{ Type of traveler } \\
\hline Solo traveler & $167(26)$ \\
\hline Young couple & $191(29)$ \\
\hline Group of friends & $102(16)$ \\
\hline Mature couple & $89(14)$ \\
\hline Family with young children & $53(8)$ \\
\hline Family with older children & $43(7)$ \\
\hline \multicolumn{2}{|l|}{ Means of travel to destination } \\
\hline Cruise Ship & $108(16)$ \\
\hline Air & $410(63)$ \\
\hline Private smaller boat & $112(17)$ \\
\hline Other (part cruise, etc.) & $23(4)$ \\
\hline
\end{tabular}

Results of study participants' outdoor activity participation (Figure 1) indicated that 66\% (429) engaged in swimming, $58 \%$ (381) in sunbathing, 47\% (309) in tourist attractions, $46 \%$ (298) sat at an outdoor deck/patio/restaurant/bar, 39\% (256) went hiking, 37\% (244) sampled local cuisine, 36\% (239) reported "seeing natural scenery" and visiting natural areas, $28 \%$ (183) went wildlife viewing or caving, and 23\% (148) went driving. Activities with the least number of participants were hunting (1\%), disc golf, boat racing, and horseshoes which saw approximately $3 \%$ participation. Scuba diving, zip lining, partying on the beach, modeling, and horseback riding were reported by $3 \%$ of study participants, even though these activities were not on the initial list of outdoor activities.

Results of the health information-seeking behavior of study participants revealed that only $21 \%$ (135) reported visiting the U.S. CDC's website for information about vector-borne diseases at their primary destination (Table 2). Only 15\% (100) reported visiting the U.S. CDC's website for information about chikungunya disease in the past, while 35\% (230) said they seek information about health risks present at a destination before visiting that destination. As regards seeking health information from the U.S. State Department's website, 19\% (124) of study participants reported looking at the website for information about mosquito-borne diseases in the Caribbean. Interestingly, about half (51\%) of the study participants said they never sought information about chikungunya or any vector-borne illnesses in the past. When asked if they had heard of chikungunya (i.e. chikungunya disease awareness) before participating in this study, only 30\% (196) of the respondents said yes, while $70 \%$ (457) said they had not (Table 3). Study participants' records of the extent to which they adopted one or more of the recommended personal protective behaviors revealed that $74 \%$ (481) used insecticides and repellents on skin or clothing when outdoors at the destination, 36\% (237) reported using bed nets, mosquito nets, insecticides, or spatial repellents, and $31 \%$ (202) reported wearing long pants, long-sleeved shirts, boots, or a hat when outdoors at the destination. Additionally, results of the analysis of study data showed that $22 \%$ (146) of study participants did not engage in any of the 3 recommended personal protective behaviors under investigation, 34\% (225) engaged in only one of the recommended behaviors, $23 \%$ (151) engaged in two of the three behaviors, and 20\% (131) engaged in all 3 recommended personal protective behaviors.

A chi-square test for independence (with Yates continuity

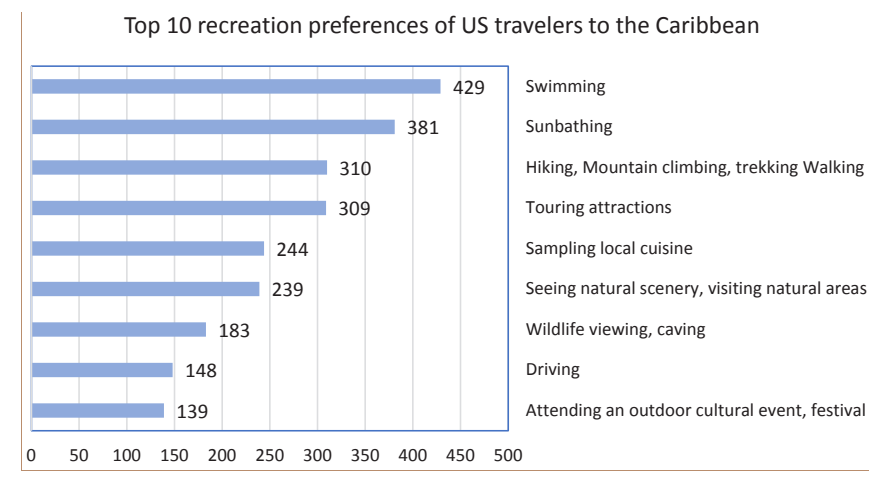

Figure 1. Recreation Preferences of a Sample of U.S. Travelers to Caribbean Destinations. 
Table 2. Study Participants' Health Information-Seeking Behavior

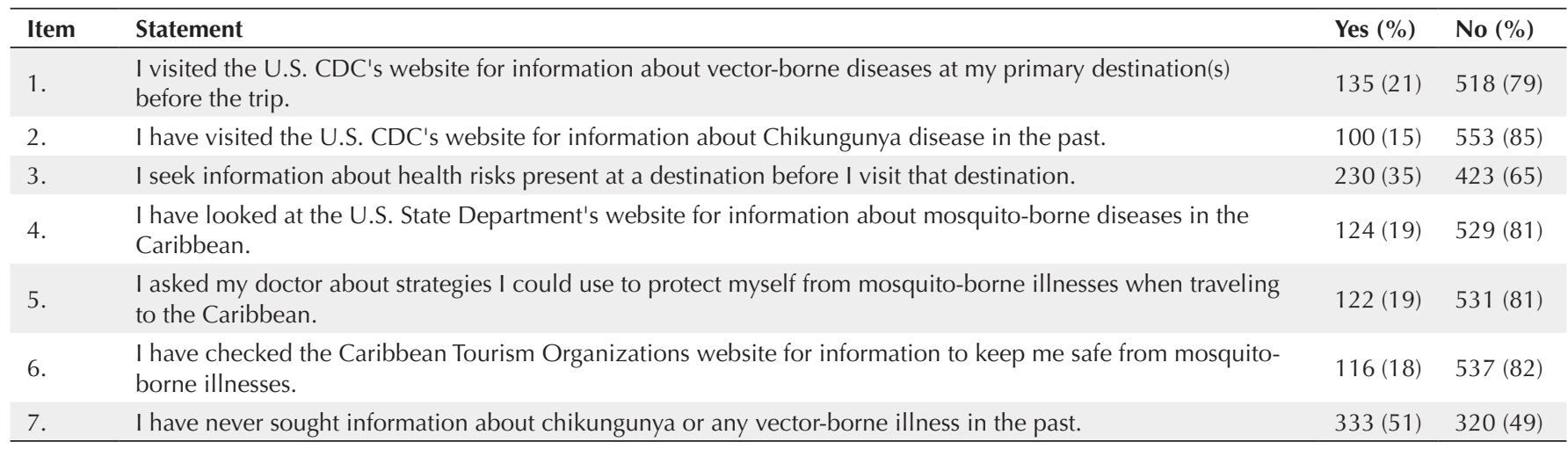

correction) showed a significant association between gender and respondent's chikungunya disease awareness $(P=.005)$, although the effect size $(\mathrm{phi}=-0.12)$ was small. ${ }^{30}$ Chisquare tests also revealed significant associations between chikungunya disease awareness and level of education $(P \leq .001)$, (phi $=0.12)$; number of days spent at the destination $(P<.001)$, even though the effect size was small (Cramer's V $=0.17)$; purpose of travel $(P=.009)$, (Cramer's $\mathrm{V}=0.13)$; and number of hours spent engaging in outdoor activities $(P \leq .001)$, (Cramer's V $=0.24$ ) (Table 4). No significant associations were found between study participants' chikungunya disease awareness and annual household income, race, employment status, and different age groups.

Unadjusted and adjusted logistic regression analyses were also performed to assess the impact of a number of factors on study participants' chikungunya disease awareness. The model contained 9 independent variables (Table 4). The adjusted logistic regression model was statistically significant $(P<.0005)$, indicating that the model was able to distinguish between respondents who reported and those who did not report chikungunya disease awareness. The model as a whole explained between 20\% (Cox \& Snell R squared) and $28 \%$ (Nagelkerke R squared) of the variance in chikungunya disease awareness and correctly classified $74 \%$ of cases.

As shown in Table 4, only 5 of the independent variables made a unique statistically significant contribution to the model at $P<.05$ (Gender, Level of education, Type of traveler, Purpose of trip, Number of days spend at the destination, and Number of hours spent engaging in outdoor activities).
Compared to males, females were two times more likely to have heard about chikungunya disease before participating in this study (odds ratio [OR] $=2.4,95 \% \mathrm{CI}$ : 1.5-3.7). After adjusting for other variables in the model, respondents who had a 2 -year college education $(\mathrm{OR}=3.3,95 \% \mathrm{CI}: 1.4-8.2)$, a 4 -year college education $(\mathrm{OR}=6.4,95 \% \mathrm{CI}$ : $2.9-14.2)$, or a graduate degree $(\mathrm{OR}=3.8,95 \% \mathrm{CI}: 1.5-10.2)$ were more likely to have chikungunya disease awareness than respondents with a high school diploma.

No statistically significant association was found between respondents' chikungunya disease awareness and annual household income, employment status, or purpose of trip. Race was not used as an independent variable in the logistic regression models, because the frequencies for the different racial groups participating in this study were not comparable (Table 4).

\section{Discussion}

Chikungunya disease is endemic in the Caribbean region and poses significant public health risks to U.S. travelers and tourists to the region. This helps explain why relevant public health agencies such as the U.S. CDC have invested in various campaigns to raise awareness and adoption of recommended personal protective behaviors among U.S. travelers to the region. This study sought to investigate the level and predictors of chikungunya disease awareness among U.S. travelers to Caribbean destinations. Additionally, the extents to which travelers adopted 3 recommended personal protective behaviors, their outdoor activity participation, and

Table 3. Chikungunya Disease Awareness and Adoption of Recommended Personal Protective Behaviors Among Study Participants

\begin{tabular}{|c|c|c|c|}
\hline Item & Statement & Yes $(\%)$ & No $(\%)$ \\
\hline 1. & Have you heard of chikungunya before today? & $196(30)$ & $457(70)$ \\
\hline 2. & I used insecticides and repellents on skin or clothing when outdoors at my primary Caribbean destination(s). & $481(74)$ & $172(26)$ \\
\hline 3. & $\begin{array}{l}\text { I used bed nets, mosquito nets, insecticides or spatial repellents when indoors at my primary Caribbean } \\
\text { destination(s). }\end{array}$ & $237(36)$ & $416(64)$ \\
\hline 4. & $\begin{array}{l}\text { I always wore long pants, long-sleeved shirts, boots, or a hat when I was outdoors at my primary Caribbean } \\
\text { destination(s). }\end{array}$ & $202(31)$ & $449(69)$ \\
\hline \multirow[t]{5}{*}{5.} & All 3 recommended personal protective behaviors & & \\
\hline & - I did not engage in any recommended protective behavior. & $146(22)$ & \\
\hline & - $\quad$ I engaged in 1 recommended protective behavior. & $225(34)$ & \\
\hline & - $\quad$ I engaged in 2 recommended protective behaviors. & $151(23)$ & \\
\hline & _ I engaged in all 3 recommended protective behaviors. & $131(20)$ & \\
\hline
\end{tabular}


Table 4. Predictors of Chikungunya Disease Awareness Among Study Participants

\begin{tabular}{|c|c|c|c|c|c|c|c|}
\hline & \multicolumn{2}{|c|}{$\begin{array}{c}\text { Have You Heard About Chikungunya } \\
\text { Disease Before Today? }\end{array}$} & \multirow[t]{2}{*}{$P$ Value ${ }^{a}$} & \multirow[t]{2}{*}{ UOR } & \multirow[t]{2}{*}{$95 \% \mathrm{Cl}$} & \multirow[t]{2}{*}{ AOR } & \multirow[t]{2}{*}{$95 \% \mathrm{Cl}$} \\
\hline & Yes & No & & & & & \\
\hline \multicolumn{8}{|l|}{ Gender } \\
\hline Male & $93(26 \%)$ & $268(74 \%)$ & .004 & 1 & & 1 & \\
\hline Female & $91(37 \%)$ & $157(63 \%)$ & & 1.7 & $1.18-2.37$ & 2.4 & $1.50-3.73$ \\
\hline \multicolumn{8}{|l|}{ Level of education } \\
\hline High school diploma & $13(14 \%)$ & $81(86 \%)$ & $<.001$ & 1 & & 1 & \\
\hline 2-year college degree & $29(25 \%)$ & $85(75 \%)$ & & 2.1 & $1.03-4.37$ & 3.3 & $1.35-8.18$ \\
\hline 4-year college degree & $125(38 \%)$ & $207(62 \%)$ & & 3.8 & $2.01-7.04$ & 6.4 & $2.92-14.19$ \\
\hline Graduate degree & $20(26 \%)$ & $56(74 \%)$ & & 2.5 & $1.02-4.84$ & 3.8 & $1.45-10.18$ \\
\hline \multicolumn{8}{|l|}{ Income } \\
\hline Less than $\$ 25000$ & $20(29 \%)$ & $49(71 \%)$ & .132 & 1 & & 1 & \\
\hline$\$ 25001-\$ 50000$ & $54(27 \%)$ & $143(73 \%)$ & & 0.9 & $.50-1.70$ & 0.5 & $.20-1.10$ \\
\hline$\$ 50001-\$ 75,000$ & $57(31 \%)$ & $127(69 \%)$ & & 1.1 & $.60-2.02$ & 0.8 & $.35-1.82$ \\
\hline$\$ 75001-\$ 100000$ & $25(28 \%)$ & $65(72 \%)$ & & 0.9 & $.47-1.89$ & 0.6 & $.21-1.50$ \\
\hline More than $\$ 100001$ & $31(44 \%)$ & $40(56 \%)$ & & 1.9 & $.94-3.83$ & 0.9 & $.35-2.42$ \\
\hline \multicolumn{8}{|l|}{ Race } \\
\hline White/European American & $129(28 \%)$ & $332(72 \%)$ & .106 & & & & \\
\hline African American & $22(39 \%)$ & $35(61 \%)$ & & & & & \\
\hline Native American & $0(0 \%)$ & $3(100 \%)$ & & & & & \\
\hline Latino/Latina & $15(41 \%)$ & $22(59 \%)$ & & & & & \\
\hline Asian & $21(38 \%)$ & $34(62 \%)$ & & & & & \\
\hline Other & $0(0 \%)$ & $3(100 \%)$ & & & & & \\
\hline \multicolumn{8}{|l|}{ Employment status } \\
\hline Employed (full-time) & $159(31 \%)$ & $356(69 \%)$ & .680 & 1 & & 1 & \\
\hline Employed (part-time) & $15(31 \%)$ & $34(69 \%)$ & & 1.0 & $.52-1.87$ & 0.5 & $.21-1.21$ \\
\hline Not employed & $13(25 \%)$ & $39(75 \%)$ & & 0.8 & $.39-1.44$ & 0.9 & $.40-2.27$ \\
\hline \multicolumn{8}{|l|}{ Age group (years) } \\
\hline $20-25$ & $42(36 \%)$ & $74(64 \%)$ & .149 & 1 & & 1 & \\
\hline $26-30$ & $51(25 \%)$ & $155(75 \%)$ & & 0.6 & $.35-.95$ & 0.3 & $.15-.55$ \\
\hline $31-35$ & $43(29 \%)$ & $104(71 \%)$ & & 0.7 & $.43-1.22$ & 0.3 & $.15-.61$ \\
\hline $36-40$ & $19(32 \%)$ & $41(68 \%)$ & & 0.8 & $.42-1.58$ & 0.8 & $.33-1.86$ \\
\hline $41+$ & $32(37 \%)$ & $55(63 \%)$ & & 1.0 & $.58-1.83$ & 0.9 & $.44-2.06$ \\
\hline \multicolumn{8}{|l|}{ Type of traveler } \\
\hline Solo traveler & $56(34 \%)$ & $111(66 \%)$ & .015 & 1 & & 1 & \\
\hline Young couple & $46(24 \%)$ & $145(76 \%)$ & & 0.6 & $.40-1.00$ & 0.5 & $.33-1.00$ \\
\hline Mature couple & $29(33 \%)$ & $60(67 \%)$ & & 1.0 & $.55-1.66$ & 0.8 & $.37-1.70$ \\
\hline Family with young children & $20(38 \%)$ & $33(62 \%)$ & & 1.2 & $.63-2.28$ & 0.5 & $.20-1.07$ \\
\hline Family with older children & $7(16 \%)$ & $36(84 \%)$ & & 0.4 & $.16-.92$ & 0.1 & $.03-.43$ \\
\hline Group of friends & $38(37 \%)$ & $64(63 \%)$ & & 1.2 & $.70-1.97$ & 1.0 & $.48-1.91$ \\
\hline \multicolumn{8}{|l|}{ Purpose of trip } \\
\hline Business & $6(23 \%)$ & $20(77 \%)$ & .009 & 1 & & 1 & \\
\hline Leisure & $178(29 \%)$ & $428(71 \%)$ & & 1.4 & $.55-3.51$ & 0.6 & $.21-1.75$ \\
\hline Business and Leisure & $12(63 \%)$ & $7(37 \%)$ & & 5.7 & $1.55-21.06$ & 2.1 & $.48-9.68$ \\
\hline \multicolumn{8}{|l|}{ No. of days spent at destination } \\
\hline $1-5$ & $35(20 \%)$ & $142(80 \%)$ & $<.001$ & 1 & & 1 & \\
\hline $6-10$ & $88(29 \%)$ & $211(71 \%)$ & & 1.7 & $1.08-2.64$ & 1.6 & $.91-2.72$ \\
\hline $11+$ & $64(41 \%)$ & $94(59 \%)$ & & 2.8 & $1.70-4.50$ & 2.0 & $1.02-3.83$ \\
\hline \multicolumn{8}{|c|}{ No. of hours spent engaging in outdoor activities } \\
\hline $0-20$ & $64(23 \%)$ & $221(73 \%)$ & $<.001$ & 1 & & 1 & \\
\hline $21-40$ & $61(33 \%)$ & $126(67 \%)$ & & 1.7 & $1.11-2.53$ & 2.5 & $1.53-4.19$ \\
\hline $41-60$ & $23(25 \%)$ & $71(75 \%)$ & & 1.1 & $.64-1.93$ & 0.9 & $.45-2.00$ \\
\hline $61-80$ & $25(53 \%)$ & $22(47 \%)$ & & 3.9 & $2.08-7.42$ & 4.2 & $1.94-9.06$ \\
\hline $80+$ & $23(58 \%)$ & $17(42 \%)$ & & 4.8 & $2.35-9.28$ & 2.6 & $1.04-6.46$ \\
\hline
\end{tabular}

Abbreviations: $U O R$, unadjusted odds ratio; $A O R$, adjusted odds ratio

a $P$ value significant at $\leq .05$. 
health information seeking behaviors were investigated.

Results of study participants' outdoor activity participation revealed that most visitors engaged in swimming, sunbathing, touring attractions, sitting at an outdoors deck/patio, hiking, sampling local cuisine, and visiting natural scenery. Conversely, the outdoor activities with the least number of participants were disc golf, boat racing, and horseshoes. These results further confirm previous evidence suggesting that outdoor activities remain a major attraction for U.S. travelers to Caribbean destinations. ${ }^{10}$

Results of study participants' health information-seeking behavior revealed that most visitors visited neither the U.S. CDC's nor the U.S. Department of State's websites for information about chikungunya disease or other health risks which might be present at the destination before traveling. In the same regard, more than $50 \%$ of study participants said they never sought information about chikungunya or any other vector-borne disease in the past. Of the large number of U.S. residents who travel each year to countries where certain infectious diseases are prevalent, Hamer and Connor ${ }^{22}$ reported that only $36 \%$ of such travelers sought travel health advice, even though more than half planned the trip at least one month in advance. Given the relatively low health information-seeking behavior observed among participants of the current study, it was not surprising that only $30 \%$ reported previous awareness of chikungunya disease before participating in this study.

The finding of a positive association between participants' chikungunya disease awareness and female gender, college educated, more days spent at the destination, and more time spent outdoors suggests possible avenues for developing interventions aimed at increasing chikungunya disease awareness. Previous studies have reported lower overall intention to adopt vector-borne disease personal protective behavior in male subjects when compared to females. ${ }^{23}$ Other studies that have reviewed gender differences in a wide variety of domains, including abilities, personality, social behavior, and memory, have produced conflicting results. ${ }^{24}$ More studies are needed to validate whether gender differences contribute significantly to chikungunya disease awareness and eventual adoption of risk-reduction behavior. While no previous studies have documented associations between levels of education, number of days spent at the destination, and time spent outdoors with chikungunya disease awareness, studies have documented a positive association between levels of education and baseline knowledge of mosquito-borne diseases. ${ }^{25,26}$ Nonetheless, Yasuoka et $\mathrm{al}^{25}$ have suggested that, regardless of sociodemographic characteristics, educational interventions are effective in increasing understanding and active involvement in preventing mosquito-borne diseases.

Study findings also indicated that the use of insecticides and repellents on skin or clothing when outdoors was the most prevalent personal protective behavior among U.S. travelers to Caribbean destinations, while wearing long pants, longsleeved shirts, boots, or a hat when outdoors was the least personal protective behaviors adopted. Previous studies have reported similar findings. ${ }^{23}$ The finding of a very low rate of adopting appropriate clothing as a chikungunya risk-reduction behavior in study participants might not be unassociated with concerns about the discomfort associated with "dressing up," especially in the warm regions of most Caribbean destinations. In addition, "dressing up" may interfere with participation and enjoyment of various outdoor activities at the destination. Furthermore, about $22 \%$ of study participants did not engage in any of the 3 recommended personal protective behaviors, while $20 \%$ engaged in all 3 protective behaviors. The U.S. Department of Defense (DoD) recommends that individuals at risk of exposure to mosquito-borne diseases should use all elements of an insect repellent system (consists of wearing a permethrin treated uniform, applying DEET or picaridin to the skin, using properly worn clothing, and using a permethrin treated bed net) for maximum protection. ${ }^{14}$ This is because all it takes for transmission of the disease is a single bite from an infected mosquito-vector. Since different components of an insect repellent system act synergistically to prevent mosquito bites, the goal should be to encourage members of an at-risk group, such as U.S. travelers to Caribbean destinations, to adopt multiple personal protective behaviors. In a study of outdoor recreationists at risk for another vector-borne disease, Omodior et $\mathrm{al}^{23}$ reported a significant association between high overall intention to adopt 3 or more recommended personal protective behaviors and actual behavior. Given that intention is considered the largest predictor of behavior), ${ }^{27}$ future studies should seek to investigate the predictors of intention vis-à-vis adoption of mosquito-borne disease personal protective behavior among U.S. travelers to Caribbean destinations.

Given the relatively low level of chikungunya disease awareness among the study participants, it is suggested that more novel approaches be considered. Carleton et $\mathrm{al}^{28}$ reviewed the evidence for the relationship between exposure to health information, awareness, knowledge, skills to change behavior, changed risky behaviors, risk factor changes, and behavior modification; they found strong evidence in support of the relationship between awareness and behavior modification. Other studies have found similar relationships between cumulative exposure to health messages, awareness, and behavior modification in at-risk groups. ${ }^{29,30}$ In a randomized controlled trial to evaluate the impact of an educational program on the prevention of tick-borne diseases, Daltroy et $\mathrm{al}^{31}$ reported a $60 \%$ risk reduction in the intervention group compared with the control group. Additionally, they observed that members of the intervention group were significantly more likely to engage in the recommended personal protective behaviors compared with the control group. In this regard, novel approaches that could be adopted based on the results of this study may involve the provision of health information within the framework of the travel and activity experience to travelers at places such as airports, car rental agencies, hotels, motels, travel agencies, event locations, etc. This approach is premised on the notion that, while travelers may not visit the U.S. CDC or Department of State's websites for information but will be visiting the destination for leisure/business, providing health information using the means by which the travel experience will be planned (i.e. travel agencies), during their travel experience (airports), where they will be staying (hotels, motels, bed and breakfasts), by the means through which they move around at the destination (car rentals), and at the venues of activity participation (events) increases the likelihood of exposure to information, awareness, knowledge 
and, ultimately, behavior modification.

The findings of this study are, however, limited to the average U.S. traveler/tourist to Caribbean destinations represented in the sample and cannot be generalized to a broader context. Another limitation of this study is that the data was collected using an online platform, which means that any segment of the population of interest without access to the internet and those not technologically savvy were missing from the sample frame. It is quite possible that a segment of the population not represented in this study (e.g., the elderly) are significantly different in some respect from the sampled population. Future studies should be designed in such a way as to sample a more representative population of U.S. travelers/tourists to Caribbean destinations. A third limitation is that this study did not adjust for variabilities that may be associated with different destinations within the Caribbean region. Future studies should also be designed to account for differences in the locations visited.

\section{Conclusion}

Although the relationship between international travel, tourism and the global spread of emerging mosquito-borne infectious diseases are known, there is little information available on the level of awareness of international U.S. travelers regarding chikungunya disease. Additionally, little information is available on the predictors of chikungunya awareness, activity participation, and adoption of recommended personal protective behaviors. This is the first study to document chikungunya disease awareness and adoption of recommended personal protective behaviors among a sample of U.S. travelers to Caribbean destinations. The findings of this study revealed that swimming, sunbathing, and touring attractions topped the list of study participants' outdoor activity participation. The findings also revealed that there is relatively low level of chikungunya disease awareness among study participants who represent U.S. travelers to Caribbean destinations. Chikungunya disease awareness significantly differs by gender, level of education, type of traveler, purpose of trip, number of days spent at the destination, and number of hours spent engaging in outdoor activities. Furthermore, the current study revealed that the use of insecticides and repellents on skin or clothing when outdoors was the most prevalent PPBs, while wearing appropriate clothing was the least adopted PPBs. Finally, the current study found that the rate of visiting the U.S. CDC's or the U.S. Department of State's websites for travel health information was low among study participants.

In spite of the limitations of this study, the findings have practical value for the implementation of interventions aimed at increasing awareness and subsequent adoption of effective personal protective behaviors among U.S. travelers to Caribbean destinations where both incidence and prevalence of emerging mosquito-borne infectious diseases are on the rise. This study also reveals that more research is needed to identify additional factors associated with chikungunya disease awareness and the adoption of recommended chikungunyarisk reduction behaviors. From a theoretical and conceptual perspective, future studies should investigate whether certain theoretical constructs, such as perceived severity, perceived
Reserach Highlights

\section{What Is Already Known?}

Evidence abounds for the relationship between international travel, tourism, and the global spread of emerging mosquito-borne infectious diseases, such as chikungunya. Infection usually results when tourists and other travelers who visit places where these infections are endemic or where outbreak events occur are bitten by infected mosquitoes. Although the U.S. CDC has embarked on a chikungunya awareness campaign for U.S. travelers to and from Caribbean destinations, the level of chikungunya awareness and the extent to which travelers to Caribbean destinations adopt the recommended personal protective behaviors remains unknown. Equally unknown is the rate of outdoor activity participation and health information-seeking behavior of U.S. travelers to Caribbean destinations.

\section{What This Study Adds?}

The current findings have practical value for the implementation of interventions aimed at increasing awareness and subsequent adoption of effective personal protective behaviors among U.S. travelers to Caribbean destinations where both incidence and prevalence of emerging mosquito-borne infectious diseases are on the rise. This study also reveals that more research is needed to identify additional factors associated with Chikungunya disease awareness and the adoption of recommended chikungunya-risk reduction behaviors.

vulnerability, response efficacy, self-efficacy, and behavioral intentions as contained in Rogers ${ }^{32}$ Protection Motivation Theory, predict adoption of recommended PPBs among U.S. travelers to Caribbean destinations.

\section{Authors' Contributions}

All authors contributed substantially to the conceptualization, writing, and review of this study.

\section{Conflict of Interest Disclosures}

Authors state they have no conflicts of interest.

\section{Ethical Approval}

The authors have addressed the relevant ethical issues. Informed consent was obtained from all participants before data collection, and the research protocol was approved by the University of Florida Institutional Review Board (IRB\#: 2015-U-1040).

\section{Funding/Support}

This study received no funding or external support.

\section{Supplementary Materials}

Supplementary file 1 contains Member list of the Caribbean Tourism Organization and Study participants list of outdoor activity.

\section{Acknowledgments}

The authors gratefully acknowledge the efforts of Edna 
Omodior in reviewing this article for grammatical errors.

\section{References}

1. Centers for Disease Control Prevention. Chikungunya fever diagnosed among international travelers--United States, 2005-2006. MMWR Morbidity and Mortality Weekly Report. 2006;55(38):1040.

2. Chen LH, Wilson ME. Dengue and chikungunya infections in travelers. Curr Opin Infect Dis. 2010;23(5):438-444. doi:10.1097/ QCO.0b013e32833c1d16.

3. Nasci RS. Movement of chikungunya virus into the Western hemisphere. Emerg Infect Dis. 2014;20(8):1394-1395. doi:10.3201/eid2008.140333.

4. Powers AM, Logue $\mathrm{CH}$. Changing patterns of chikungunya virus: reemergence of a zoonotic arbovirus. J Gen Virol. 2007;88(9):23632377.

5. Gubler DJ. The economic burden of dengue. Am J Trop Med Hyg. 2012;86(5):743-744. doi:10.4269/ajtmh.2012.12-0157.

6. Sharp TM, Jomil Torres M, Ryff KR, Chanis Mercado M, del Pilar M. Chikungunya cases identified through passive surveillance and household investigations-Puerto Rico, May 5-August 12, 2014. Morbidity and Mortality Weekly Report. 2014;63(48);1121-8.

7. Leparc-Goffart I, Nougairede A, Cassadou S, Prat C, De Lamballerie X. Chikungunya in the Americas. Lancet. 2014;383(9916):514. doi:10.1016/S0140-6736(14)60185-9.

8. McElroy JL. Tourism development in small islands across the world. Geografiska Annaler Series B Human Geography. 2003;85(4):231242.

9. Carribbean Tourism Organization. Latest Tourism Statistics Tables http://www.onecaribbean.org/statistics/latest-tourism-statisticstables/. Published 2015

10. Dodds R. Report for Caribbean Soft Adventure Study. Caribbean Regional Sustainable Tourism Development Programme. Contract No.: Project No. 8 ACP RCA 035. Barbados; 2006.

11. Villareal A. High-End Vacationers Cancel Caribbean Trips Because of Chikungunya. http://observer.com/2014/12/high-endvacationers-cancel-caribbean-trips-because-of-chikungunya/. Published 2014.

12. US Centers for Disease Control \& Prevention. Chikungunya Information for Vector Control Programs. http://www.cdc.gov/ chikungunya/pdfs/CHIKV_VectorControl.pdf. Published 2015.

13. Nasci RS, Zielinski-Gutierrez E, Wirtz RA, Brogdon WG. Protection against mosquitoes, ticks, \& other insects \& arthropods. CDC Health Information for International Travel: The Yellow Book. Atlanta: CDC; 2014

14. US Army Public Health Center. DoD Insect Repellent System https://phc.amedd.army.mil/topics/envirohealth/epm/Pages/ DoDInsectRepellentSystem.aspx. Published 2016.

15. Chikungunya in the Caribbean. US CDC website. http://wwwnc. cdc.gov/travel/notices/watch/chikungunya-caribbean. Updated March 2015. Published 2015.

16. Fact Sheets and Posters 2015. US CDC website. http://www.cdc. gov/chikungunya/fact/index.html.

17. The 2016 Florida Statutes. http://www.leg.state.fl.us/statutes/ index.cfm?App_mode=Display_Statute $\& U R L=0100-0199 / 0125 /$ Sections/0125.0104.html. Published 2016

18. Hendee JC, Gale RP, Catton WR. A typology of outdoor recreation activity preferences. J Environ Educ. 1971;3(1):28-34.

19. Kil N, Holland S, Taylor S. Improving the management of natural resource recreation areas through understanding place-attached visitor segments. J Park Recreat Admi. 2010;28(3).

20. Ho R. Predicting intention for protective health behaviour: a test of the protection versus the ordered protection motivation model. Aust J Psychol. 2000;52(2):110-118.

21. Cohen J. Statistical power analysis. Curr Dir Psychol Sci. 1992;1(3):98-101.

22. Hamer DH, Connor BA. Travel health knowledge, attitudes and practices among United States travelers. J Travel Med. 2004; $11(1): 23-26$.

23. Omodior O, Pennington-Gray L, Donohoe H. Efficacy of the theory of planned behavior in predicting the intention to engage in tick-borne disease personal protective behavior amongst visitors to an outdoor recreation center. J Park Recreat Admi. 2015;33(2).

24. Hyde JS. The gender similarities hypothesis. Am Psychol. 2005;60(6):581-592.

25. Yasuoka J, MangioneTW, Spielman A, Levins R. Impact of education on knowledge, agricultural practices, and community actions for mosquito control and mosquito-borne disease prevention in rice ecosystems in Sri Lanka. Am J Trop Med Hyg. 2006;74(6):1034-42.

26. Itrat A, Khan A, Javaid S, et al. Knowledge, awareness and practices regarding dengue fever among the adult population of dengue hit cosmopolitan. PloS One. 2008;3(7):e2620. doi:10.1371/journal. pone.0002620.

27. Ajzen I. The theory of planned behavior. Organ Behav Hum Decis Process. 1991;50(2):179-211.

28. Carleton RA, Bazzarre T, Drake J, Dunn A, Fisher EB, Grundy SM, et al. Report of the expert panel on awareness and behavior change to the board of directors, American Heart Association. Circulation. 1996;93(9):1768-1772.

29. Kaskutas LA, Graves K. Relationship between cumulative exposure to health messages and awareness and behavior-related drinking during pregnancy. Am J Health Promot. 1994;9(2):115-124.

30. Green-Raleigh K, Carter H, Mulinare J, Prue C, Petrini J. Trends in folic acid awareness and behavior in the United States: the Gallup Organization for the March of Dimes Foundation surveys, 19952005. Matern Child Health J. 2006;10(5 Suppl):S177-82.

31. Daltroy LH, Phillips C, Lew R, Wright E, Shadick NA, Liang MH. A controlled trial of a novel primary prevention program for Lyme disease and other tick-borne illnesses. Health Educ Behav. 2007;34(3):531-42.

32. Rogers R. Cognitive and physiological processes in fear appeals and attitude change: a revised theory of protection motivation. In: Cacioppo DJ, Petty R, eds. Social Psychophysiology. New York: Guildford Press; 1983:153-176. 